\section{Medical researchers set up UK body to raise public profile}

[LONDON] An organization representing the professional int erests of academic medicine is to be set up in Britain in an effort to raise the public profile of the biomedical sciences.

The establishment of the Academy of Medical Sciences was announced last week by a coordinating committee whose members include representatives of the Royal Society, the royal medical colleges, and university medical schools.

This group, which has been meeting for the past two years under the chairmanship of Peter Lachmann, the biological secretary of the Royal Society, will act as the academy's interim council until it formally begins its activities in October. The academy will initially have $\mathbf{3 5 0}$ founder fellows, but the eventual aim is to increase the fellowship to 1,000 over the next ten years.

According to proposals drawn up by the coordinating committee, the academy will seek to promote the practical application and public understanding of medical resear $\mathrm{ch}$. It also plans to advise the government and other public bodies on issues related to medical sciences that pervade policy decisions.

One important role will be to bridge the gap between basic research in the biomedical sciences and clinical practice. "We aim to create an int egrated body which can provide expert advice on issues of national interest," Christopher Edwards, principal of Imperial College School of Medicine and a member of the coordinating committee, said at a press conference last week.

Previous attempts to establish a professional body for the medical sciences have met with opposition from some parts of both the Royal Society and the medical colleges, on the grounds that it would duplicate some of their own functions. But, according to Edwards, recent issues emerging from scientific advances, such as cloning and bovine spongiform encephalopathy (BSE), have highlighted a need for a professional body representing the interests of medical research.

Members of the coordinating committee say that issues likely to be addressed by the academy include the effect of biotechnology on the medical sciences and the ethical aspects of cloning. It may set up a subcommittee on ethical issues, bringing together a wide range of experts and perhaps carrying out joint studies with other organizations.

Welcoming the cr eation of the new academy, Sir Aaron Klug, president of the Royal Society, said that "the lack of a unified voice for academic medicine has been apparent for some time particularly on those issues of science, science policy and science support that embrace all the sciences". Asako Saegusa

\title{
Japan backs carbon project in shift to applied research
}

[TOKYO] Japan's Ministry of International Trade and Industry (MITI) is actively backing an ambitious large-scale national research and development project designed to produce 'highly functional carbon and related materials'.

The move reflects a shift in the focus of MITI's sup port for research and development from basic towards more applied research, as part of its efforts to help restructure and stimulate Japan's economy by contributing to the growth of new industries.

The five-year project into the possible application of carbon materials - including fullerenes, carbon nanotubes, carbon nitride and diamond-like carbon - is one of several industry-orientated research projects being launched this year by MITI's Agency of Industrial Science and Technology (AIST).

MITI officials say there has been a policy decision to encourage the establishment of new competitive industries in response to the current poor economic conditions, following the cabinet approval last May of plans to reform the Japanese economy.

Harutoshi Yamada of AIST says that building new industries and technologies is a priority for the government. The relative lack of venture-capital-based businesses, combined with a reluctance by university professors to establish their own companies, means the ministry must actively encourage promising technologies, he says. "In Japan, everything cannot be left to the market."

The government is backing this strategy. Despite an austere budget for the new fiscal year that starts in April, leaving overall government expenditure virtually flat, MITI won a relatively large increase of 4.3 per cent in its research and development budget (see Nature 391, 111; 1998).

Over the past few years the powerful ministry, internationally renowned for its active industrial policy and encouragement of new technologies, has increasingly focused its attention on nurturing basic research and turning its 15 national research institutes into international "centres of excellence".

But ministry officials acknowledge that the focus has switched to creating new technologies and industries. The new Frontier Carbon Technology Project, an illustration of this shift, will be based at MITI's National Institute of Materials and Chemical Research (NIMC) in Tsukuba, northwestofTokyo.

The project will receive $¥ 1.4$ billion (US\$12 million) each year over a five-year period. Researchers will work on synthesis and materialization technologies for highly functional carbon and related materials. Yoshinori Koga, a senior researcher at the

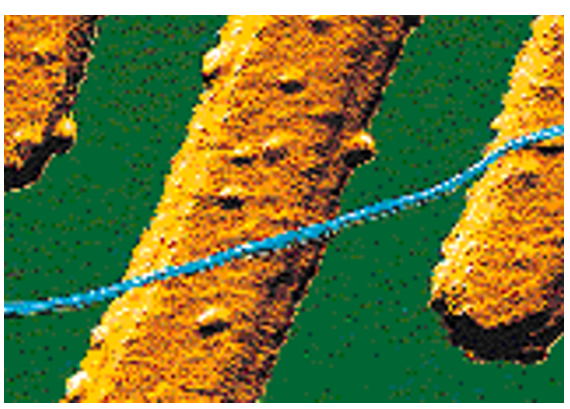

Narrow research: the world's smallest electrical wire is just a dozen or so carbon atoms wide.

institute, says this could lead to the development of new devices, semiconductors and materials for use in flat panel displays.

The project has received wide support from academics and industry in Japan, which has relatively strong research on nanotubes and fullerenes. Yohji Achiba, a leading Japanese chemist and researcher into fullerenes at Tokyo Metropolitan University, argues that the time has come to make a national effort to promote such research, as it is essential for the country's future to take the financial risks involved in supporting research that might not deliver the results anticipated.

One company to welcome the project is the electronics manufacturer NEC, a world leader in research into fullerenes and carbon nanotubes. "We would like to expand our research activities through the project," says Hisatsune Watanabe, vice-president of NEC's research and development group.

He says the project offers the opportunity to create new devices to control photons, such as scanning near-field optical microscopes, as well as the chance to work with companies from different fields.

Not all sup porters of the carbon project are optimistic that it will lead to the creation of new industries. Although it might be politically important for MITI to be seen to be expanding industrial activity in Japan, argues one senior industry expert, the creation of these indust ries "is not so easy", as applications are still a long way off.

The project will be funded through the New Energy and Industrial Technology Development Organization and will link researchers at NIMC with industry and universities in a focused group under a new 'concentrated research and development system'.

Other new MITI research projects being launched this year include a large-scale genome programme aimed at developing technologies for decoding and using genetic information, and a superconductor application technology programme. Richard Nathan 